\title{
The Glycemic Index, Postprandial Hypotension and Cardiovascular Disease
}

\section{Mini Article}

Volume 1 Issue 1- 2021

Author Details

Ayan Agarwal ${ }^{1}$, Ezzah Inayat ${ }^{2}$, Fred Liang ${ }^{3}$, Jessica Wanyan ${ }^{4}$, Keishini Selvaganesh ${ }^{5}$, Madumitha Balaji $^{6}$, Matthew Martinez $^{7}$, Nora Lang ${ }^{8}$, Serena Trang 9 , Aleksandra Bourdine ${ }^{10}$, Araz Derohan ${ }^{11}$, Aruchana Umaharan ${ }^{12}$, Arya Ebrahimzadeh Ahari ${ }^{13}$, Christina Zhong ${ }^{14}$, Duygu Cevik ${ }^{15}$, Fariha Kibria ${ }^{16}$, Felix Hu${ }^{17}$, Gabriela Landim Araujo ${ }^{18}$, Jack Yassa ${ }^{19}$, Laiba Adnan ${ }^{20}$, Maaria Kasmani $^{21}$, Mariah Hassam ${ }^{22}$, Md Abrar Kashfi Jahin ${ }^{23}$, Md Faiyaz Kashfi Rian ${ }^{24}$, Michelle Wong ${ }^{25}$, Muskaan Dhuka ${ }^{26}$, Niloufer Fatima Syeda ${ }^{27}$, Rebecca Luo ${ }^{28}$, Samuel-Caleb Yeung ${ }^{29}$, Shayaan Kaleem ${ }^{30}$, Shilpa Tandon ${ }^{31}$, Wayne Sun ${ }^{32}$, Zaim Khan ${ }^{33}$, Zakir Hossain $^{34}$, Abu Bakar Butt ${ }^{35}$, Ashanth Santhiran ${ }^{11}$, Edna Estefania Cofles Gualtero ${ }^{36}$, Ethan Zhang ${ }^{29}$, Jorane-Tiana Robert ${ }^{37}$, Tess Coppinger $^{38}$, Minji Kim ${ }^{39}$, Melanie Paquette ${ }^{40,41}$, Sandhya Sahye-Pudaruth ${ }^{40,41}$, Darshna Patel ${ }^{40,41}$, John L Sievenpiper ${ }^{40-43}$, David JA Jenkins ${ }^{40-43}$

${ }^{1}$ Vardhman Mahavir Medical College and Safdarjung Hospital, New Delhi, India

${ }^{2}$ Department of Interdisciplinary Sciences, McMaster University, Canada

${ }^{3}$ Department of Physiology and Immunology, University of Toronto, Canada

${ }^{4}$ Department of Human Biology, McMaster University, Canada

${ }^{5}$ Faculty of Health Sciences, McMaster University, Canada

${ }^{6}$ Department of Kinesiology and Health Science, York University, Canada

${ }^{7}$ Department of Psychology, University of Ottawa, Canada

${ }^{8}$ Department of Health Sciences, Queen's University, Canada

${ }^{9}$ Faculty of Health Sciences, University of Western Ontario, Canada

${ }^{10}$ Faculty of Arts \& Science, University of Toronto, Canada

${ }^{11}$ Department of Biological Sciences, University of Toronto, Canada

${ }^{12}$ Department of Physiology \& Pharmacology, Western University, Canada

${ }^{13}$ School of Nutrition, Ryerson University, Canada

${ }^{14}$ Department of Biochemistry, University of Western Ontario, Canada

${ }^{15}$ Department of Biology, McMaster University, Canada

${ }^{16}$ School of Nutrition, Ryerson University, Canada

${ }^{17}$ Faculty of Health Sciences, McMaster University, Canada

${ }^{18}$ Department of Life Science, University of Toronto, Canada

${ }^{19}$ Department of Medicine, National University of Ireland Galway (NUIG), Canada

${ }^{20}$ Department of Chemistry and Biology, Ryerson University, Canada

${ }^{21}$ School of Medicine, University College of Dublin, Canada

${ }^{22}$ Faculty of Science, Ontario Tech University, Canada

${ }^{23}$ Department of Medical Sciences, University of Western Ontario, Canada

${ }^{24}$ Department of Nursing, Ryerson University, Canada

${ }^{25}$ Schulich School of Medicine \& Dentistry, University of Western Ontario, Canada

${ }^{26}$ Department of Biology, University of Waterloo, Canada

${ }^{27}$ Department of Kinesiology \& Health Sciences, York University, Canada

${ }^{28}$ St. Robert Catholic High School, Canada

${ }^{29}$ Faculty of Science, University of Western Ontario, Canada

${ }^{30}$ Department of Molecular Genetics, University of Toronto, Canada

${ }^{31}$ School of Interdisciplinary Science, McMaster University, Canada

${ }^{32}$ Department of Biomedical and Molecular Sciences, Queen's University, Canada

${ }^{33}$ Department of Biochemistry and Biomedical Sciences, McMaster University, Canada

${ }^{34}$ Department of Fisheries Biology and Genetics, Agricultural University, Bangladesh

${ }^{35}$ Faculty of Health, University of Waterloo, Canada

${ }^{36}$ Department of Science, Ryerson University, Canada

${ }^{37}$ Department of Biology and Health sciences, University of Toronto, Canada

${ }^{38}$ Department of community services, Ryerson University, Canada

${ }^{39}$ School of Medicine, University of Toronto, Canada

${ }^{40}$ Department of Nutritional Sciences, University of Toronto, Canada

${ }^{41}$ Clinical Nutrition and Risk Factor Modification Centre, St. Michael's Hospital, Canada

${ }^{42}$ Department of Medicine, University of Toronto, Canada

${ }^{43}$ Li Ka Shing Knowledge Institute, St. Michael's Hospital, Canada

*Corresponding author

David JA Jenkins, Department of Nutritional Sciences, Temerty Faculty of Medicine, University of Toronto, Clinical Trials Unit, Clinical Nutrition and Risk Factor Modification Centre, St. Michael's Hospital, Department of Medicine, Temerty Faculty of Medicine, University of Toronto, Division of Endocrinology and Metabolism, Department of Medicine, St. Michael's Hospital, Li Ka Shing Knowledge Institute, St. Michael's Hospital, Toronto, ON, Canada

Article History

Received: August 08, 2021 Accepted: August 16, 2021 Published: August 23, 2021 


\begin{abstract}
High glycemic index diets have been associated with an increased risk of cardiovascular disease events and all-cause mortality. We suggest that part of the reason for this association is through the effect of the rapidly digested high glycemic index carbohydrate diets in promoting the effects of postprandial hypotension in vulnerable individuals.

Postprandial hypotension has been recognized as a problem especially affecting the frail elderly. The phenomenon occurs earlier in the day and includes syncope and falls acutely and more serious cardiovascular events and increased all-cause mortality in the longer-term. The mechanism appears to relate to the rapid digestion of carbohydrates foods. Strategies that reduce the amount of meal carbohydrates and their rate of absorption by enzyme inhibition or by delaying gastric emptying and have proved helpful as has increased fluid intake, presumably due to dilution of small intestinal contents and a reduction in the tonicity, so reducing the need for intestinal fluid secretion to dilute osmotically active sugars and products of digestion. In this way the need for increased blood flow to the gut can be reduced, that would otherwise steal blood from the systemic circulation resulting in a drop in blood pressure and an increase in heart rate. Slowly absorbed or low glycemic index carbohydrates would therefore appear potentially useful as part of the dietary strategy for the treatment of postprandial hypotension and conversely postprandial hypotension could be one of the reasons why high glycemic index diets have been associated with increased CVD risk.
\end{abstract}

\section{Introduction}

Despite carbohydrates being the major macronutrient consumed by a majority of the human population, there is an increasing concern that certain carbohydrates may increase the risk of all-cause mortality and cardiometabolic disease [1]. "Low-carb" diets have consequently been advocated in the form of the Atkins, Paleo, and Keto diets [2]. Paradoxically, government and health agencies have been increasingly advocating for plant-based diets rich in carbohydrate foods; fruits, vegetables, whole grains, and legumes [3]. A less recognized analysis of the Prospective Urban Rural Epidemiology (PURE) cohort also demonstrated that certain carbohydrate foods, including fruits, vegetables, and legumes, are protective of all-cause mortality [4]. The most recent assessment of the PURE study indicated that high glycemic index (GI) diets were associated with total and cardiovascular disease (CVD) mortality and posed the question as to why these events occurred [5]. Was the damage that resulted in CVD and death related to the postprandial glycemic effects of carbohydrate foods in, for example glycating proteins? Or was it instead the effect of their rate of absorption on intestinal blood flow and postprandial hypotension or was it both?

\section{Postprandial Hypotension and Tachycardia}

We propose that postprandial hypotension (PPH) and associated tachycardia induced by a high GI diet may be one of the factors contributing to CVD (including fatal arrhythmias, thrombus formation, and strokes) associated with consumption of a high GI diet. Postprandial hypotension is defined as a fall of $\geq 20 \mathrm{mmHg}$ in systolic blood pressure in the first 2 -hours after eating [6,7]. This frequently under-recognized phenomenon has been increasingly reported in the elderly, as well as individuals with hypertension, diabetes, Alzheimer, Parkinson and other autonomic dysfunctions [8,9]. Furthermore, $\mathrm{PPH}$ which is most severe in the morning [8], is also associated with orthostatic hypotension and may lead to syncope, angina, and stroke [7]. This timing for response with breakfast and higher carbohydrate intakes.

A prospective cohort study with an elderly population across 4.7 years found PPH to be an independent predictor of all cause-mortality rates increased risk of syncope, angina, stroke and death $[10,11]$. Therefore, there is evidence indicating the dangers of postprandial hypotension.

\section{Possible Causes}

a. Acute effects: Possible factors that may increase the risk include autonomic neuropathy as in diabetes with impaired sympathetic compensation for meal induced increased splanchnic blood flow (mesenteric steal). It is also seen with increasing age, together with impaired baroreceptor reflex activity, insulin induced vasodilation, impaired peripheral vasoconstriction and the secretion of vasodilatory gastrointestinal polypeptides [7].

b. Chronic effects: We believe that the damage to nerves and arteries that leads to vulnerability to postprandial hypotension may be in part the result of increased oxidative damage. Such damage may result from large glycemic excursions as seen on high glycemic index diets. Following this damage as seen with aging, diabetes, prediabetes, and hypertension etc., the autonomic nervous system damage renders the individual vulnerable to acute effects of postprandial hypotension and associated tachycardia.

We see this process as having two stages leading to increased CVD risk. First, rapidly absorbed carbohydrate foods (high GI) increases oxidative damage to the autonomic nervous system. Then the subsequent postprandial hypotension may precipitate the following events: syncope, stroke, angina, myocardial infarction, arrhythmias, and heart failure.

\section{Oxidative Stress as the Initial Insult from High GI Diets}

High GI foods are associated with increased postprandial glucose responses, which cause increasing fluctuations in blood glucose throughout the day. Furthermore, the mean amplitude of glycemic excursion (MAGE) has been associated with increased oxidative stress [12], which in turn has been associated with an increased risk of CVD, possibly related to oxidative damage to lipids, proteins, and enzyme systems (e.g., through oxidation of the LDL particle, ultimately increasing its atherogenicity and uptake into the arterial wall by the scavenger system, leading to plaque formation) $[13,14]$. Of the many markers of oxidative damage, one of the most robust and stable is 8-iso-prostaglandin F2alpha (8-iso-PGF2 $\alpha$ ), which is the oxidative product of arachidonic acid. The production of 8-iso-PGF2 $\alpha$ has been shown to increase with increasing MAGE, and its urinary output correlates well with the magnitude of glucose excursions [12].

\section{BMI as a Risk Factor}

Research has suggested that those with a higher body mass index (BMI), specifically obese individuals defined as having a BMI of $>30 \mathrm{~kg} /$ $\mathrm{m}^{2}$, tend to suffer with a significantly greater drop in postprandial blood pressure in comparisons with non-obese individuals [15]. Furthermore, a study involving elderly patients demonstrated that both higher BMI and postprandial hypotension increased the risk of developing CVD [16]. It is possible this greater drop in blood pressure may be due to autonomic dysfunction and subsequent reduction of sympathetic tone in obese individuals [15].

As stated previously, autonomic dysfunction is known to be associated with diabetes - a disease that may result from obesity. Additionally, the 
glycemic index appears to apply most strongly to those with a higher BMI [17]. Theoretically, these factors would put obese individuals at a greater risk of post prandial hypotension and consequently CVD. However, there has not been sufficient research in this area to verify a link between the two.

\section{Acarbose, as a Drug Model for the Effects of Slow Absorption on Diabetes and CVD}

Acarbose is the drug model for a low glycemic index diet. By reducing the rate of digestion and absorption of carbohydrate, it effectively converts diets with normal to higher glycemic index diets into low glycemic index diets. Acarbose has been also shown to reduce the development of diabetes and also CVD in the STOP NIDDM (Study to Prevent Non-Insulin-Dependent Diabetes Mellitus) trial by 49\% [18]. This effect of Acarbose did not reach significance in a large study in China [19]. However, in that study $66 \%$ of the participants were taking beta-blockers that would directly reduce postprandial tachycardia and so potentially obscure the potential benefits of the effects of Acarbose on postprandial tachycardia. In the STOP NIDDM trial, only $21 \%$ of participants were taking any form of cardiovascular drug [18] and in the recent cohort study [20] that showed the association of high GI diets with CVD death, only $4 \%$ of the participants were taking beta-blockers. Of particular interest in this respect is the metaanalysis demonstrating the ability of Acarbose to reduce the risk of postprandial hypotension [18].

\section{The Glycemic Index and Unanswered Questions}

Our recent publication indicated a significant association in the PURE cohort between GI and cardiovascular mortality (HR 1.26, 95\% CI 1.12-1.41, P<0.001) [20]. When PURE study data were added to a recent WHO commissioned meta-analysis [21], a very strong association was seen. This finding poses the question of the mechanism (as discussed above) by which GI and CVD deaths are linked, thereby allowing logical preventive strategies to be developed. Together with cancer, CVD remains one of the two major causes of mortality in Western nations, with its rate rapidly rising in developing countries.

As already discussed a high GI diet may increase the risk of CVD by several mechanisms. The same postprandial events that contribute to diabetes and prediabetes, also increase the risk of CVD. Ceriello and colleagues have suggested that increased free radical production results from large (MAGE) glycemic excursions and contributes to higher rates of insulin resistance [22]. In this respect, the measurement of 8 -iso-PGF2 $\alpha$, a marker of oxidative stress, has been shown to correlate with the mean amplitude of glucose excursions MAGE in type 2 diabetes when measured with continuous glucose monitoring (CGM) throughout the day. This oxidation product of arachidonic acid has been shown to be increased by another prooxidant stress, namely cigarette smoking, that is associated with increased CVD risk [23]. Free radical damage to lipids, proteins, including lipoproteins have in turn been hypothesized as contributing to CVD [24]. Steinberg and colleagues, proposed the association between oxidized LDL particles and CVD over 20 years ago [25], and reviewed the accumulated evidence for the process whereby oxidized LDL was preferentially taken up by the scavenger receptors in the arterial wall, contributing to plaque buildup [26]. Such plaques have been considered to promote an inflammatory response [27]. Ridker showed in the CANTOS (Canakinumab Anti-Inflammatory Thrombosis Outcomes Study) trial that a reduction in inflammation is directly related to fewer CVD events (and reduced cancer deaths) in at-risk populations [28]. These long-term mechanisms may also link high GI diets with increased CVD risk. We believe that the acute post-meal effects of high GI foods, together with longer-term oxidative damage resulting from a high GI diet, both require further investigation.

\section{Treatment OPTIONS}

Reducing the total carbohydrate load, slowing the rate of digestion and absorption are all potential treatment options (Table 1) [29-34]. The symptoms can be relieved by somatostatin injection [7] that reduces the rate of gastric emptying and for similar reasons GLP1, used in diabetes treatment, will probably also work. In addition mealtime administration of Acarbose [35,36], the alpha glucosidase inhibitor that inhibits digestion and absorption not only of disaccharidases, sucrase and isomaltase, in the small intestine brush border but also pancreatic amylase in the gut lumen, has been shown to reduce postprandial hypotension [37]. By reducing the rate of breakdown and absorption of starch and disaccharide sugars, these alpha glucosidase inhibitor drugs effectively convert the diet into a low GI diet. With a reduced rate of small intestinal digestion and absorption of carbohydrate. The stimulus for vasodilation of the splanchnic bed is also reduced. In this way the transfer of fluid and gastrointestinal secretions to the lumen of the gut (Figure 1) from the vascular compartment is the need to all fluid to maintain the tonicity of the intraluminal small intestinal contents. Viscous fibers that are also known to delay gastric emptying (such as pectin or guar gum) and to reduce the rate of absorption and the risk of postprandial hypotension when mixed with the meal. In this respect low GI foods by virtue of the slower rate of digestion can therefore also be expected to reduce postprandial hypotension.

Table 1: Pharmacological interventions for treatment of postprandial hypotension and the corresponding physiology.

\begin{tabular}{|c|c|c|c|c|c|c|c|}
\hline Drug & Dosage & Route & Schedule & Results & Proposed Physiology & Adverse Effects & References \\
\hline GLP-1 agonists & $0.9 \mathrm{pmol} / \mathrm{kg} / \mathrm{min}$ & $\begin{array}{c}\text { Intravenous } \\
\text { infusion }\end{array}$ & $\begin{array}{c}\text { Half hour } \\
\text { before till 2 } \\
\text { hours after } \\
\text { oral glucose }\end{array}$ & $\begin{array}{c}\text { GLP 1 } \\
\text { attenuated the } \\
\text { fall in SBP and } \\
\text { DBP }\end{array}$ & $\begin{array}{c}\text { GLP 1 decreases Superior } \\
\text { Mesenteric Artery flow by } \\
\text { slowing down the gastric } \\
\text { emptying }\end{array}$ & None \\
\hline $\begin{array}{c}\text { DPP 4 } \\
\text { nhibitors } \\
\text { (Sitagliptin) }\end{array}$ & 25mg & Oral & $\begin{array}{c}\text { Just after } \\
\text { waking up }\end{array}$ & $\begin{array}{c}\text { Sitagliptin } \\
\text { reduced the } \\
\text { postprandial } \\
\text { hypotension }\end{array}$ & $\begin{array}{c}\text { DPP } 4 \text { inhibitors inhibit } \\
\text { the metabolism of GLP 1 } \\
\text { and increase GLP 1 levels } \\
\text { which delays the gastric } \\
\text { emptying }\end{array}$ & None & [30] \\
\hline Guar gum & $9 \mathrm{~g}$ & Oral & $\begin{array}{c}\text { With the } \\
\text { meal }\end{array}$ & $\begin{array}{c}\text { Guar gum } \\
\text { significantly } \\
\text { reduced the } \\
\text { postprandial } \\
\text { hypotension } \\
\text { after oral glucose }\end{array}$ & $\begin{array}{c}\text { Guar gum slows the gastric } \\
\text { emptying and glucose } \\
\text { absorption }\end{array}$ & None \\
\hline
\end{tabular}




\begin{tabular}{|c|c|c|c|c|c|c|c|}
\hline Acarbose & 50 or $100 \mathrm{mg}$ & Oral & $\begin{array}{l}\text { Once daily } \\
\text { at breakfast } \\
\text { time }\end{array}$ & $\begin{array}{l}\text { Acarbose could } \\
\text { significantly } \\
\text { attenuate the } \\
\text { decrease of } \\
\text { postprandial } \\
\text { SBP }\end{array}$ & $\begin{array}{l}\text { Acarbose inhibits brush } \\
\text { border disaccharidases and } \\
\text { pancreatic amylase, thus, } \\
\text { inhibiting postprandial } \\
\text { splanchnic perfusion }\end{array}$ & $\begin{array}{l}\text { Bloating } \\
\text { Abdominal } \\
\text { distension } \\
\text { Diarrhea }\end{array}$ & {$[32]$} \\
\hline Octreotide & $0.5 \mathrm{mcg} / \mathrm{kg}$ & $\begin{array}{l}\text { Subcutaneous } \\
\text { injection }\end{array}$ & $\begin{array}{l}\text { After } 15 \mathrm{~min} \\
\text { of start of } \\
\text { breakfast }\end{array}$ & $\begin{array}{l}\text { Octreotide } \\
\text { prevented the } \\
\text { postprandial } \\
\text { hypotension }\end{array}$ & $\begin{array}{l}\text { Octreotide is a splanchnic } \\
\text { vasoconstrictor and } \\
\text { increases cardiac output }\end{array}$ & $\begin{array}{l}\text { Gastrointestinal } \\
\text { complaints e.g., } \\
\text { diarrhea }\end{array}$ & {$[33]$} \\
\hline Caffeine & $100 \mathrm{mg}$ & Oral & $\begin{array}{c}\text { After the } \\
\text { meal }\end{array}$ & $\begin{array}{l}\text { Caffeine } \\
\text { attenuated the } \\
\text { postprandial } \\
\text { hypotension } \\
\text { while sitting }\end{array}$ & $\begin{array}{l}\text { Caffeine stimulates } \\
\text { sympathetic nervous } \\
\text { system, renin angiotensin } \\
\text { system and also, blocks } \\
\text { vasodilatory adenosine } \\
\text { receptors in the splanchnic } \\
\text { circulation }\end{array}$ & None & [34] \\
\hline
\end{tabular}
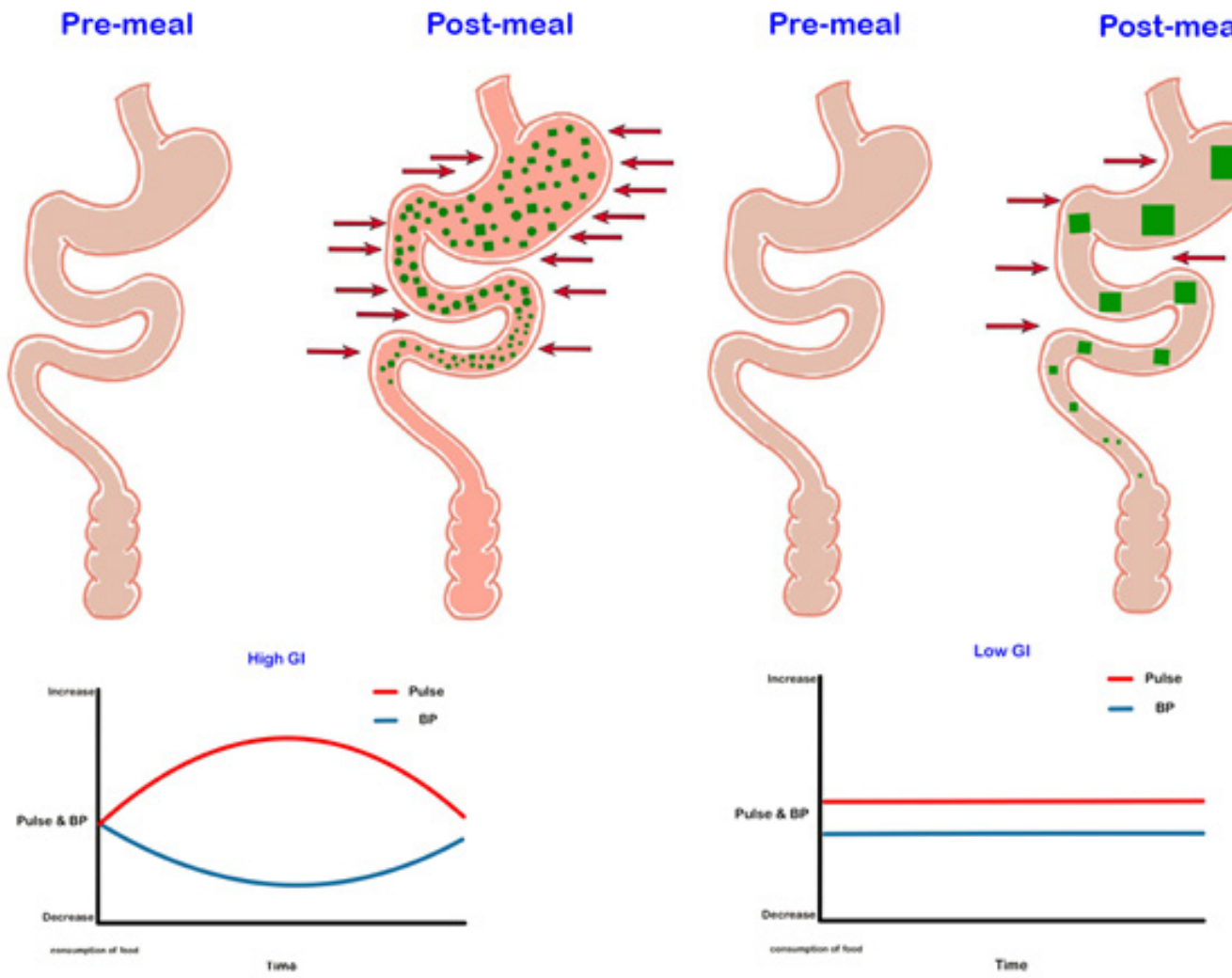

Figure 1: Schematic representation of effects of rapid and slow digestion on the gastrointestinal tract indicating effects of rapid absorption in increasing the amount of osmotically active small molecular spices that draw in fluid to the lumen of the bowel from these splanchnic circulation and hence from this systemic circulation resulting in arise in pulse and fall in blood pressure (bottom of this figure).

\section{Glycemic Index Studies Required}

Therefore, it is important to test foods with both high and low GIs to determine their effects on postprandial hypotension in both healthy and vulnerable individuals. Vulnerable individuals may include those with diabetes, autonomic neuropathy, decreased vasomotor control, and individuals of older age. Tests would determine the potential of foods with different rate if digestion to increase pulse and lower blood pressure (BP) after consumption. As mentioned it must be noted that there is a $49 \%$ increase in strokes occurring between the hours of 6 am to $12 \mathrm{pm}$. This time period covers the post-breakfast period where high GI meals may have been consumed [38,39].

\section{Conclusion}

There is significant evidence that high GI diets are associated with an increased risk of CVD and all-cause mortality. Such effects may relate to postprandial hypotension and tachycardia, induced by carbohydraterich foods, especially those with a high GI. Simultaneously, waves of hyperglycemia from low GI diets will damage tissue proteins via glycation and oxidative stress, making individuals more vulnerable to the acute effects of postprandial hypotension and tachycardia. Therefore, we believe that individuals who take a higher GI diet increase their risk of experiencing cardiovascular events and all-cause mortality. 


\section{References}

1. Dehghan M, Mente A, Zhang X, Swaminathan S, Li W, et al. (2017) Associations of fats and carbohydrate intake with cardiovascular disease and mortality in 18 countries from five continents (PURE): a prospective cohort study. Lancet 390(10107): 2050-2062.

2. Sukkar SG, Muscaritoli M (2021) A Clinical Perspective of Low Carbohydrate Ketogenic Diets: A Narrative Review. Front Nutr 8 642628.

3. Nestle M, Jacobson MF (2000) Halting the obesity epidemic: a public health policy approach. Public Health Rep 115(1) :12-24.

4. Miller V, Mente A, Dehghan M, Rangarajan S, Zhang X, et al. (2017) Fruit, vegetable, and legume intake, and cardiovascular disease and deaths in 18 countries (PURE): a prospective cohort study. Lancet 390(10107): 2037-2049.

5. Livesey G, Livesey H (2019) Coronary Heart Disease and Dietary Carbohydrate, Glycemic Index, and Glycemic Load: Dose-Response Meta-analyses of Prospective Cohort Studies. Mayo Clin Proc Innov Qual Outcomes 3(1): 52-69.

6. Grodzicki T, Rajzer M, Fagard R, O’Brien ET, Thijs L, et al. (1998) Ambulatory blood pressure monitoring and postprandial hypotension in elderly patients with isolated systolic hypertension. Systolic Hypertension in Europe (SYST-EUR) Trial Investigators. J Hum Hypertens 12(3): 161-165.

7. Jansen RW, Lipsitz LA (1995) Postprandial hypotension: epidemiology, pathophysiology, and clinical management. Ann Intern Med 122(4): 286-295.

8. Vloet LC, Smits R, Jansen RW (2003) The effect of meals at different mealtimes on blood pressure and symptoms in geriatric patients with postprandial hypotension. J Gerontol A Biol Sci Med Sci 58(11): 10311035

9. Lipsitz LA, Nyquist RP, Wei JY, Rowe JW (1983) Postprandial reduction in blood pressure in the elderly. N Engl J Med 309(2): 81-83.

10. Fisher AA, Davis MW, Srikusalanukul W, Budge MM (2005) Postprandial hypotension predicts all-cause mortality in older, low-level care residents. J Am Geriatr Soc 53(8): 1313-1320.

11. Goyal P, Maurer MS (2016) Syncope in older adults. J Geriatr Cardiol 13(5): 380-386.

12. Monnier L, Mas E, Ginet C, Michel F, Villon L, et al. Activation of oxidative stress by acute glucose fluctuations compared with sustained chronic hyperglycemia in patients with type 2 diabetes. Jama 295(14): 1681-1687.

13. Griendling KK, FitzGerald GA (2003) Oxidative stress and cardiovascular injury: Part II: animal and human studies. Circulation 108(17): 2034-2040.

14. Dhalla NS, Temsah RM, Netticadan T (2000) Role of oxidative stress in cardiovascular diseases. J Hypertens 18(6): 655-673.

15. Sequeira A, Rosario D (2016) A Comparative Study of Pre and Postprandial BP Recordings in Obese and Non Obese Young Adults. J Clin Diagn Res 10(1): 1-3.

16. Jang A (2020) Postprandial Hypotension as a Risk Factor for the Development of New Cardiovascular Disease: A Prospective Cohort Study with 36 Month Follow-Up in Community-Dwelling Elderly People. J Clin Med 9(2).

17. Vega-López S, Venn BJ, Slavin JL (2018) Relevance of the Glycemic Index and Glycemic Load for Body Weight, Diabetes, and Cardiovascular Disease. Nutrients 10(10)

18. Chiasson JL, Josse RG, Gomis R, Hanefeld M, Karasik A, et al (2003) Acarbose treatment and the risk of cardiovascular disease and hypertension in patients with impaired glucose tolerance: the STOPNIDDM trial. Jama 290(4): 486-494.

19. Holman RR, Coleman RL, Chan JCN, Chiasson JL, Feng H, et al. (2017) Effects of acarbose on cardiovascular and diabetes outcomes in patient with coronary heart disease and impaired glucose tolerance (ACE): a randomised, double-blind, placebo-controlled trial. Lancet Diabetes Endocrinol 5(11): 877-886.

20. Jenkins DJA, Dehghan M, Mente A, Bangdiwala SI, Rangarajan S, et al (2021) Glycemic Index, Glycemic Load, and Cardiovascular Disease and Mortality. N Engl J Med 384(14): 1312-1322.

21. Reynolds A, Mann J, Cummings J, Winter N, Mete E, et al. (2019) Carbohydrate quality and human health: a series of systematic reviews and meta-analyses. Lancet 393(10170): 434-445.

22. Ceriello A (2005) Postprandial hyperglycemia and diabetes complications: is it time to treat? Diabetes 54(1): 1-7.

23. Morrow JD, Frei B, Longmire AW, Gaziano JM, Lynch SM, et al. (1995) Increase in circulating products of lipid peroxidation (F2-isoprostanes) in smokers. Smoking as a cause of oxidative damage. N Engl J Med 332(18): 1198-1203

24. Steinberg D (1997) Low density lipoprotein oxidation and its pathobiological significance. J Biol Chem 272(34): 20963-20966.

25. Steinberg D, Parthasarathy S, Carew TE, Khoo JC, Witztum JL (1989) Beyond cholesterol. Modifications of low-density lipoprotein that increase its atherogenicity. N Engl J Med 320(14): 915-924.

26. Steinberg D, Witztum JL (2010) Oxidized low-density lipoprotein and atherosclerosis. Arterioscler Thromb Vasc Biol 30(12): 2311-2316.

27. Ross R (1999) Atherosclerosis--an inflammatory disease. N Engl J Med 340(2): 115-126.

28. Ridker PM, Everett BM, Thuren T, MacFadyen JG, Chang WH, et al. (2017) Antiinflammatory Therapy with Canakinumab for Atherosclerotic Disease. N Engl J Med 377(12): 1119-1131.

29. Trahair LG, Horowitz M, Stevens JE, Christine Feinle-Bisset, Scott Standfield, et al. (2015) Effects of exogenous glucagon-like peptide-1 on blood pressure, heart rate, gastric emptying, mesenteric blood flow and glycaemic responses to oral glucose in older individuals with normal glucose tolerance or type 2 diabetes. Diabetologia 58(8): 1769-1778.

30. Saito Y, Ishikawa J, Harada K (2016) Postprandial and Orthostatic Hypotension Treated by Sitagliptin in a Patient with Dementia with Lewy Bodies. Am J Case Rep 17: 887-893.525.

31. Jones KL, MacIntosh C, Su YC, Wells F, Chapman IM, et al. (2001) Guar gum reduces postprandial hypotension in older people. J Am Geriat Soc 49(2): 162-167.

32. Wang B, Zhao J, Zhan Q, Wang R, Liu B, et al. (2021) Acarbose for Postprandial Hypotension With Glucose Metabolism Disorders: A Systematic Review and Meta-Analysis. Front Cardiovasc Med 8: 663635.

33. Robert D Hoeldtke, Gabriella G Horvath, Kimberly D Bryner, Gerald R Hobbs (1998) Treatment of Orthostatic Hypotension with Midodrine and Octreotide. The Journal of Clinical Endocrinology \& Metabolism 83(2): 339-343.

34. Heseltine D, el-Jabri M, Ahmed F, Knox J (1991) The effect of caffeine on postprandial blood pressure in the frail elderly. Postgrad Med J 67(788): 543-547.

35. Shibao C, Gamboa A, Diedrich A, Dossett C, Choi L, et al. (2007) Acarbose, an alpha-glucosidase inhibitor, attenuates postprandial hypotension in autonomic failure. Hypertension 50(1): 54-61.

36. Zhang J, Guo L (2017) Effectiveness of acarbose in treating elderly patients with diabetes with postprandial hypotension. J Investig Med 65(4): 772-783.

37. Jenkins DJ, Taylor RH, Goff DV, Fielden H, Misiewicz JJ, et al. (1981) Scope and specificity of acarbose in slowing carbohydrate absorption in man. Diabetes 30(11): 951-954.

38. Elliott WJ (1998) Circadian variation in the timing of stroke onset: a meta-analysis. Stroke 29(5): 992-996.

39. Marler JR, Price TR, Clark GL, Muller JE, Robertson T, et al. (1989) Morning increase in onset of ischemic stroke. Stroke 20(4): 473-476. 